\title{
Análisis regional de Colombia y su maldición de recursos naturales: cambios institucionales tardíos
}

Luis Reina-Bermúdez. Universidad Nacional Abierta y a Distancia (UNAD), Bogotá, Colombia.

Didier Alejo-Barrera. Universidad Externado de Colombia, Bogotá, Colombia.

Neider Devia-Merchan. Universidade Federal de Roraima (UFRR), Boa Vista, Brasil.

RESUMEN | Para verificar la existencia de maldición de recursos naturales (RN), y sus efectos regionales en Colombia, el texto se dispone como sigue: (i) introducción; (ii) marco teórico; (iii) análisis de las estructuras económicas de las regiones; (iv) análisis del marco institucional; y (v) conclusiones. La revisión bibliográfica aborda la creciente preocupación sobre el papel de los RN en la dinámica y estructura económica, bajo denominaciones como enfermedad holandesa ( $\mathrm{EH}$ ) o maldición de RN. El análisis de datos de Colombia en los años 2000-2013 evidencia que en el país existió EH basada en el auge del petróleo. Dicha EH tiene efectos regionales diferenciados, aunque atípicos en la región de auge de RN: la Orinoquía. Tras un análisis institucional, se concluye que, pese a las recientes reformas institucionales, la existencia de la EH tendrá efectos nocivos a largo plazo en términos de crecimiento, debido al choque de precios a la baja del petróleo.

PALABras ClAVE | desigualdades regionales, ajuste económico, geografía económica.

ABSTRACT | To verify the presence of the curse of natural resources (NR), and its regional effects in Colombia, this article is structured as follows: (i) Introduction; (ii) Framework; (iii) Analysis of the economic structures of the regions; (iv) Institutional context analysis; and $v$ ) conclusions. The literature review addressing the growing concern about the role of $N R$ in the dynamic and economic structure, under names such as Dutch Disease (DD) or NR curse. Data analysis between the years 2000-2013, shows that in Colombia, DD existed based on the oil boom. DD has differentiated regional effects, although atypical effects in the region with NR boom: Orinoco. After an institutional analysis, it is concluded that the existence of $D D$ will have long-term harmful effects in terms of growth, due to the collapse of oil prices.

KEYwORDs | regional inequalities, economic adjustment, economic geography.

Recibido el 19 de octubre de 2015, aprobado el 25 de mayo de 2016.

E-mails: L. Reina-Bermúdez, luis.reina@unillanos.edu.co | D. Alejo-Barrera, didier.alejo@unillanos.edu.co |

N. Devia-Merchan, nadeviam@ut.edu.co 


\section{Introducción}

En los últimos trece años, Colombia buscó el desarrollo económico a través de la explotación de sus recursos naturales (RN), con énfasis en la minería y el petróleo, lo que llevó a exponerse a los efectos de la "enfermedad holandesa". ${ }^{1}$ Este trabajo se realiza con el objetivo de analizar los efectos de dicha enfermedad, originada por el auge de recursos naturales en las regiones de Colombia, en especial en la región de la Orinoquía, lo que finalmente llevaría al país a la "maldición de los recursos naturales".2

Para demostrar lo anterior y comprender los efectos producidos en la economía de un país con auge de RN, se hace una revisión de la literatura y se contrasta con datos del periodo 2000 a 2013, tratando de evidenciar los síntomas y la dinámica regional que implica la concentración de la producción en la actividad minera.

Por otro lado, se discute sobre las decisiones adoptadas por el Estado para enfrentar los efectos de la enfermedad holandesa y la decisión de enfocarse únicamente en la minería, dejando a un lado otros sectores importantes para el desarrollo de un país. Puesto que dichos puntos de explotación -los relativos a la minería- no compensan la falta de un desarrollo regional equilibrado sectorialmente junto a la población existente, ha ido apareciendo el descontento de los habitantes con las políticas manejadas para el desarrollo de estas actividades en la región.

\section{Marco teórico}

Existe una amplia literatura que relaciona los efectos negativos que se producen entre un auge en recursos naturales y el desempeño económico. Las principales denominaciones en literatura son: a) la maldición de los recursos naturales (Gelb, 1988; Gylfason, 1999; Sach \& Warner, 1995, 1997, 1999); b) la enfermedad holandesa (Bruno \& Sach, 1982; Cosakoff \& Campanario, 2006); y c) una versión más refinada de las consecuencias adversas de un auge de RN, explicada por la teoría staple trap, trampa de la grapa (Auty, 1997, 2001; Auty \& Gelb, 2000; Willebald, 2011). Los efectos se agudizan o reducen según la estructura económica y el marco institucional del país.

Es de destacar que dentro de la primera orientación del desarrollo (véase al respecto Escobar, 2005) se encuentran algunos trabajos acerca de cómo aprovechar un auge en recursos naturales para conseguir un crecimiento balanceado (big push literature) (Murphy, Shleifer \& Vishny, 1989; Rosenstein-Rodan, 1943, 1961), noción recientemente retomada por Collier (2006). Pero es precisamente la refutación de los beneficios del big push lo que hacen Sach y Warner (1999), al demostrar para una serie de países de América Latina que un big push trajo de hecho una disminución del PIB per cápita.

1 Véase subtítulo Enfermedad holandesa.

2 Véase subtítulo Maldición de recursos naturales. 


\section{Enfermedad holandesa}

En relación con los big push, la enfermedad holandesa es precisamente el desajuste en la estructura productiva que impide un crecimiento compensado. Por el contrario, dicho crecimiento se hace extremadamente dependiente del RN en auge. La enfermedad holandesa (Dutch disease) está relacionada con el efecto en el tipo de cambio que termina afectando el sector de transables exportados en una economía (Piraján, Urrea \& Gutiérrez, 2012).

Siguiendo a Jean-Philippe Stijns (2003), pueden señalarse cuatro efectos tangibles para percibir la presencia de enfermedad holandesa: (i) una apreciación del tipo de cambio; (ii) el aumento de producción de no transables; (iii) disminución de la producción manufacturera; y (iv) disminución de las exportaciones manufactureras. Los efectos segundo y tercero tendrían una explicación teóricamente ambigua, ${ }^{3}$ mientras que los efectos primero y cuarto son claros empírica y teóricamente.

Las diferentes investigaciones han mostrado los efectos de la enfermedad holandesa en la estructura productiva nacional, suponiendo, por ejemplo, pleno empleo, y que la inversión de capital es totalmente externa. También han diferenciado los efectos directos de los indirectos en los sectores con bienes transables (como industria y agricultura). El efecto directo sobre los sectores con transables es el causado por la apreciación de la tasa de cambio, que afecta su rentabilidad, lo que impulsa decrecimiento en estos sectores. El efecto indirecto es causado por la transferencia de recursos de producción a otros sectores, que se da esencialmente porque el auge en RN incrementa la demanda mundial y los precios de los bienes y servicios no transables.

En Colombia, trabajos precedentes han estudiado los efectos del auge en RN basados en la agricultura, buscando evidencia de enfermedad holandesa (Wunder, 1991). Otros han propuesto el período 2000-2010 como uno en que Colombia experimentó la enfermedad holandesa basada en la explotación minera, principalmente petrolera (Piraján et al., 2012).

\section{Maldición de los recursos naturales}

La teoría sobre la maldición de los recursos naturales surgió luego de que Sach y Warner $(1995,1999)$ refutaran la hipótesis de que un auge en RN podría servir como impulso al crecimiento a largo plazo y probaran que, por el contrario, la tasa normal de crecimiento disminuía una vez que dicho auge pasaba. Bulmer-Thomas (1994, p. 334) demostró que, en América Latina, todas las experiencias de auges fracasaron. La explicación conceptualmente más rica del porqué esto ocurre la ofrece la teoría de la "trampa de la grapa" (staple trap), que se presenta adelante.

La base de la supuesta maldición de los recursos naturales es la siguiente: dada una dotación abundante de recursos naturales, se desarrolla una estructura productiva y social concentrada sectorial y poblacionalmente, que se torna persistente y

3 La explicación sería ambigua porque depende de la magnitud del efecto en la demanda del sector en auge. La producción de no transables se afecta positivamente por el incremento en la demanda generada por el sector en auge, y negativamente por la caída de las exportaciones. Igualmente, la producción manufacturera (y en general las anteriores exportaciones tradicionales) se afecta negativamente por la apreciación del tipo de cambio, pero el aumento en demanda generado por el sector en auge la beneficia. 
que afecta el desempeño económico de los países (Acemoglu \& Robinson, 2012; Auty, 2001; Engerman \& Sokoloff, 1994, 2002). La posibilidad de desarrollar rentas fiscales sobre este RN en auge lleva a una pereza fiscal en principio, y probablemente a políticas públicas que exageran el gasto (Auty, 2001; Perry \& Olivera, 2009), agravadas en algunos casos por la corrupción (Gylfason, 2000).

Engerman y Sokoloff $(1994,2002)$ enfatizaron que las estructuras productivas que les fue posible desarrollar a las excolonias de las Américas, dadas sus ventajas comparativas, fueron determinantes en la formación y persistencia de sus instituciones. En ello radicaría la diferencia entre las excolonias españolas (sustentadas en la extracción de recursos naturales, como oro, o en cultivos más productivos que en Europa con ventaja comparativa [vc]), y algunas excolonias británicas que, debido a sus condiciones medioambientales similares a las europeas, desarrollaron una economía más o menos equitativa (Willebald, 2011). Willebald explica que, con el tiempo, las regiones de Australia que fueron incorporándose como fronteras agrícolas tuvieron aún mejores distribuciones de la tierra que las europeas. Entre tanto, las regiones con fronteras agrícolas de Sudamérica se conformaron desigualmente.

Jefrey Frankel (2012, pp. 3-4, traducción libre) planteó seis hipótesis del porqué los RN se tornan una maldición: (i) tendencia a largo plazo de los precios mundiales de los commodities; (ii) volatilidad en los precios de los commodities; (iii) incremento permanente en los sectores no manufactureros, donde se cree que los efectos indirectos se concentran; (iv) instituciones autocráticas u oligárquicas; (v) instituciones anárquicas, reflejadas en indefiniciones en los derechos de propiedad y rápidos agotamientos de RN (consumo insostenible), e incluso guerra civil o conflicto interno; (vi) expansión cíclica de los sectores no transables debido a la enfermedad holandesa. (Respecto del punto tercero, incremento de los sectores no manufactureros, véase también Sachs \& Warner, 1995).

Por consiguiente, es importante, con relación a la maldición de los recursos naturales, diferenciar entre recursos puntuales y recursos difusos. Los primeros, como los minerales y los recursos energéticos, son intensos en el uso del capital, mientras que los recursos difusos, como la tierra y la ganadería, no lo son. "Los recursos puntuales generan mayores oportunidades de captación de rentas; la corrupción y los efectos negativos sobre el crecimiento económico son más graves" (Willebald, 2011, p. 88).

La hipótesis de la apropiabilidad se refiere a la posibilidad de captación de rentas derivadas de los RN (Boschini, Pettersson \& Roine, 2007). La apropiabilidad es la probabilidad de la apropiación de un RN, con la captura de sus rentas o el desarrollo de estrategias anticompetitivas, o simplemente corrupción (Boschini et al., 2007). Dicha hipótesis plantea que la abundancia de RN, conjuntamente con la apropiabilidad, llevan a determinar el desempeño económico a largo plazo, tomando en cuenta que el nivel de apropiabilidad es definido por el contexto institucional (Willebald, 2011, p. 179). La maldición de los recursos naturales se presentaría entonces allí donde es inadecuado el contexto institucional (en función de mayores niveles de apropiabilidad y en presencia o aparición de un RN abundante).

Para Willebald (2011), los aportes recientes sobre la maldición de recursos naturales se centran en: “(i) las características intrínsecas de los recursos naturales en cuestión (el efecto de la abundancia varía en función del tipo de los recursos 
naturales), y (ii) la calidad de las instituciones en términos de su capacidad para abrir posibilidades de apropiabilidad de los ingresos basados en el capital natural” (p. 88).

\section{Modelo de la trampa de la grapa (staple trap)}

La trampa de la grapa (o del crecimiento basado en pocos recursos) consiste en explotar un RN determinado bajo un marco institucional favorable al despilfarro, la pereza fiscal y de los empresarios, especialmente industriales, que resultan beneficiados de medidas proteccionistas (Auty, 2001).

Una característica de los países ricos en RN es la presencia de disputas políticas entre facciones que buscan aprovechar el alto nivel de apropiabilidad de los RN, cuyas rentas son asignadas a simpatizantes dentro de la facción para facilitar la continuidad en el poder (Auty \& Gelb, 2000, p. 3).

Según el modelo de la trampa de la grapa, los países pobres en recursos naturales tienden a desarrollar estados 'desarrollistas', con una serie de condiciones institucionales que los ayudan a un crecimiento rápido, sostenido y equitativo. De ser emulados por los países ricos en recursos naturales, tal tendencia podría ayudarlos a no caer en la trampa del crecimiento grampeado. Las condiciones de las instituciones mencionadas, según Auty (2001), son:

- Un Estado benevolente que busca el bienestar social a largo plazo o una democracia consensuada.

- Acceso relativamente equitativo a la tierra y a la educación primaria.

- Mantenimiento de una política comercial abierta.

- Gasto público transparente y mercados eficientes.

Retomando la hipótesis de la apropiabilidad, la razón por la cual se cae en la trampa del crecimiento grampeado es que el contexto institucional público es débil, lo que quiere decir que difiere de las condiciones antes expuestas, como constatan Isham, Woolcock, Pritchett y Busby (2005) y Woolcock, Pritchett e Isham (2001). Ello facilita la alta apropiabilidad de los RN en auge y sus rentas. Así, al producirse la apropiación, el país experimenta menores tasas de crecimiento de lo que podría en condiciones diferentes, ya que, además del crecimiento descompensado, aumentan sus niveles de inequidad (Willebald, 2011, p. 88).

Trabajos empíricos, entre ellos los de Mehlun et al. (2006) y Van der Ploeg (2006), usan nociones como el imperio de la ley para mostrar los niveles de institucionalidad que podrían desencadenarse o evitar la maldición de RN. Areski y Van der Ploeg (2007), por su parte, no trabajan la apropiabilidad conceptualmente, pero sí en su concreción de posibilidades de expropiación y corrupción, a través del uso del índice de gobernabilidad de la Guía Internacional de Riesgo País (ICRG, por sus siglas en inglés). 
Una síntesis de teorías de relación negativa entre RN y desempeño económico, y cómo prevenir o atenuar los efectos del auge

La figura 1 es un esquema del proceso que muestra cómo los países con abundancia de recursos podrían caer o no en la trampa de la grapa del crecimiento, que los llevaría en el corto plazo a experimentar una enfermedad holandesa y cambios en la estructura productiva; y a largo plazo, a experimentar la maldición de los recursos naturales.

\section{FIgura I | Proceso de la maldición de recursos naturales}

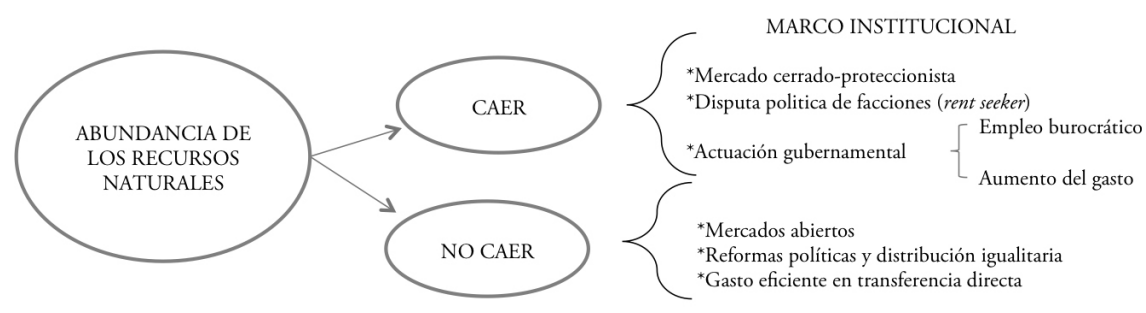

FUENTE ELABORACIÓN PROPIA

En cuanto a la prevención o atenuación de los efectos de un auge en recursos naturales, se pueden resumir, por una parte, en la adopción de las medidas institucionales descritas en la figura 1; y por otra, en la tradicional medida de aprovechar el auge para modernizar la industria a través de la inversión en capital, como también la inversión en infraestructura física de transporte y energía. Birdsall, Pindkney y Sabot, 1999) probablemente presentan una excepción al proponer una priorización de dichos recursos en la educación.

\section{Metodología y tabla de datos}

Para el trabajo aquí planteado se recopilaron las cuentas nacionales colombianas por departamento y por sector a precios constantes ańo del 2005 para los años de estudio, reportadas por el Departamento Administrativo Nacional de Estadística (DANE), a las cuales se les dio el siguiente tratamiento: se sumaron las cuentas departamentales subsectoriales y se unificaron en cinco sectores, que corresponden a: (i) el sector agropecuario, que engloba la agricultura, la pesca y silvicultura; (ii) el sector de minería, que agrupa la explotación de metales e hidrocarburos; (iii) la industria manufacturera; (iv) el sector de la construcción; y (v) el sector servicios, que engloba los servicios públicos, el comercio, restaurantes y reparaciones, los servicios de transporte, almacenamiento, los servicios financieros e impuestos (servicios del Estado). Estos sectores departamentales se agruparon según las regiones, las cuales quedaron conformadas por departamentos (figura 2). 
FIGURA 2 | Regiones de Colombia

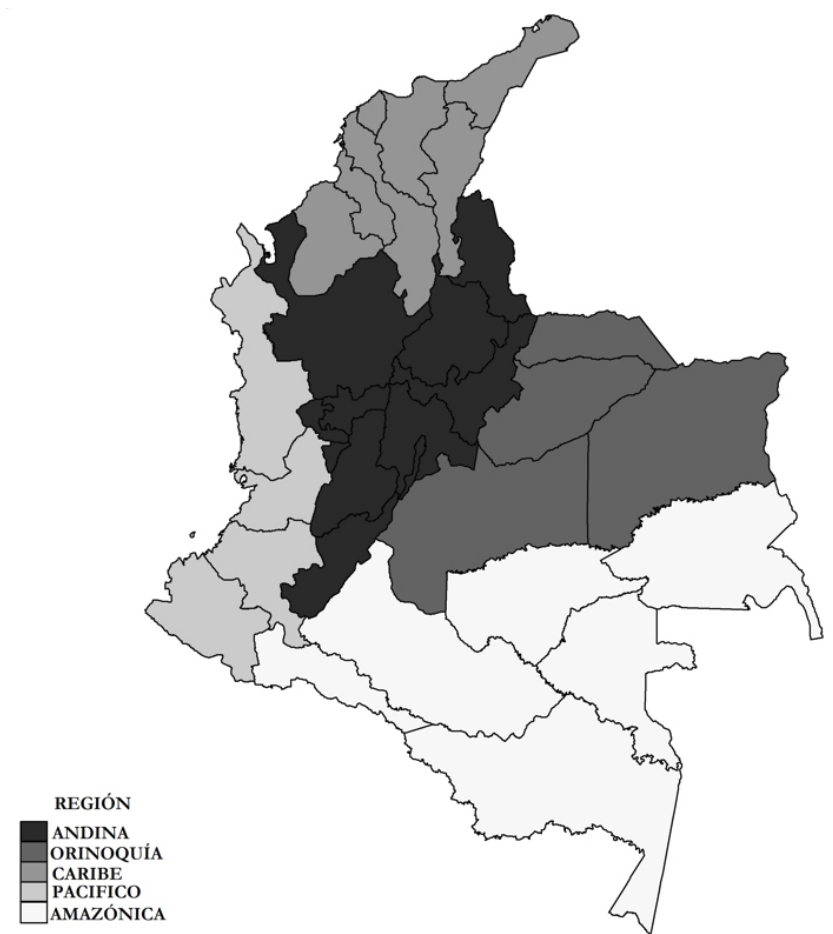

NOTA REGIÓN ANDINA: HUILA, TOLIMA, BOGOTÁ, CUNDINAMARCA, BOYACÁ, CALDAS, RISARALDA, QUINDÍO, ANTIOQUIA, SANTANDER Y NORTE DE SANTANDER. REGIÓN ORINOQUÍA: ARAUCA, CASANARE, META Y VICHADA. REgIÓN CARIBE: GUAJIRA, CESAR, BOLÍVAR, CÓRDOBA, MAGDAlena, SUCRE, ATLÁNTICO, SAN ANDRÉS. REgión PACífico: CHOCÓ, VAlle DeI CAUCA, CAUCA Y NARIÑO. REgIÓN AMAZÓNICA: CAQUETÁ, PUTUMAYO, GUAVIARE, GUAINÍA, AMAZONAS Y VAUPÉS.

FUENTES DEPARTAMENTO ADMINISTRATIVO NACIONAL DE ESTADÍSTICA (DANE), TASAS DE CRECIMIENTO PARA LOS AÑos DE ESTUdio; Y TASAS DE CAMBIO REPRESENTATIVAS DEL MERCAdo (TRM) REPORTADAS POR EL BANCO DE LA REPÚBLICA DE COLOMBIA, AÑOS DE ESTUDio

A partir de esta información, se elaboraron gráficas tanto de participación para los ańos 2000, 2002, 2006, 2010, 2013, como también de las tasas de crecimiento promedio para los periodos 2000-2002, 2003-2006, 2007-2010 y 2011-2013. También se construyeron dos tablas, la primera con datos de exportaciones tradicionales y no tradicionales, y la segunda con valores de producto por sector en los años inicial y final de la serie 2000 y 2013. Adicional a esto se analizó la evolución del tipo de cambio en el periodo dado. Basados en estas tablas y las gráficas incluidas, se analizan los impactos en cada región de la enfermedad holandesa que presenta Colombia en el periodo de estudio, y se discute la pertinencia de las medidas desplegadas en materia de redistribución de regalías. 


\section{Análisis de las estructuras económicas}

La composición regional del sector agropecuario muestra un aumento en la participación de la Orinoquía, pese a que la teoría señala que, por efectos de la enfermedad holandesa, este sector se vería deteriorado, ya que parte de su producto es transable. De hecho, el sector agropecuario como un todo creció en el periodo a buen ritmo, siendo la participación de la Orinoquía determinante. Aparentemente, esta situación se debe a un incremento en el área de cultivo y/o cantidades de producto.

Este aumento de la participación de la región Orinoquía en el sector agropecuario nacional es explicado por la inversión de grandes empresarios enfocados en la producción de monocultivos, con lo cual la región estaría compensando los efectos adversos de RN mineros, ampliando y expandiendo la frontera agropecuaria, como se puede observar en la gráfica de crecimiento promedio del sector agropecuario (figura 3). Es de resaltar que la tasa real de crecimiento del sector agrícola colombiano en el periodo 2000-2013 fue de 35,1\% y que las participaciones de las demás regiones no varían para el periodo de estudio.

FIGURA 3 | Participación porcentual y tasas de crecimiento promedio del sector Agropecuario

\section{Panel a}

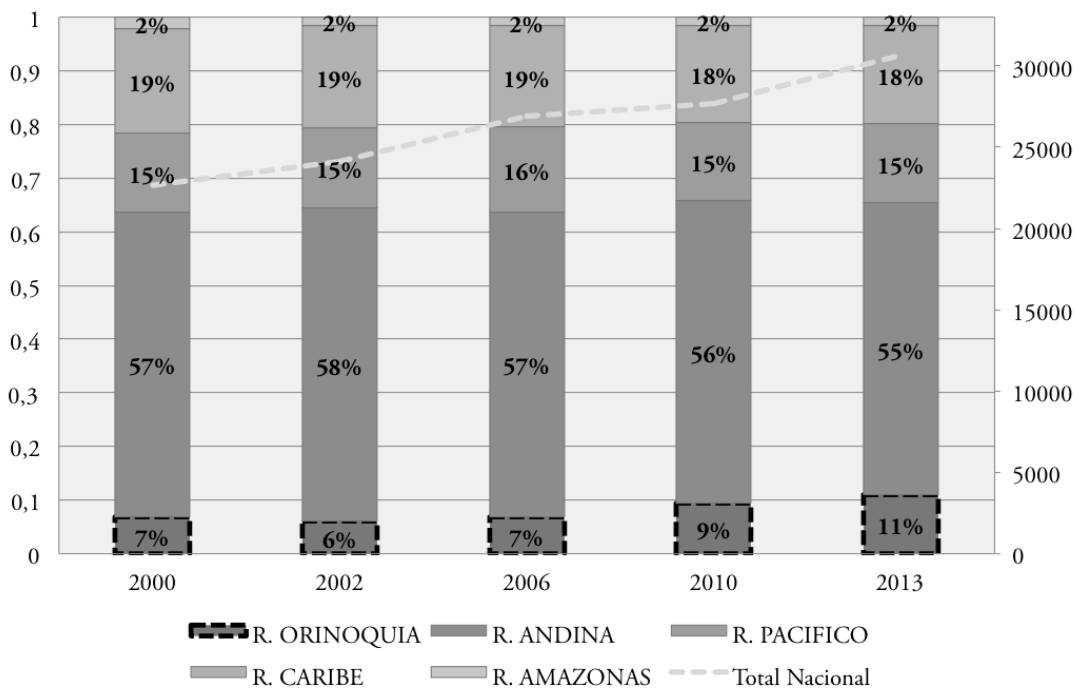




\section{Panel b}

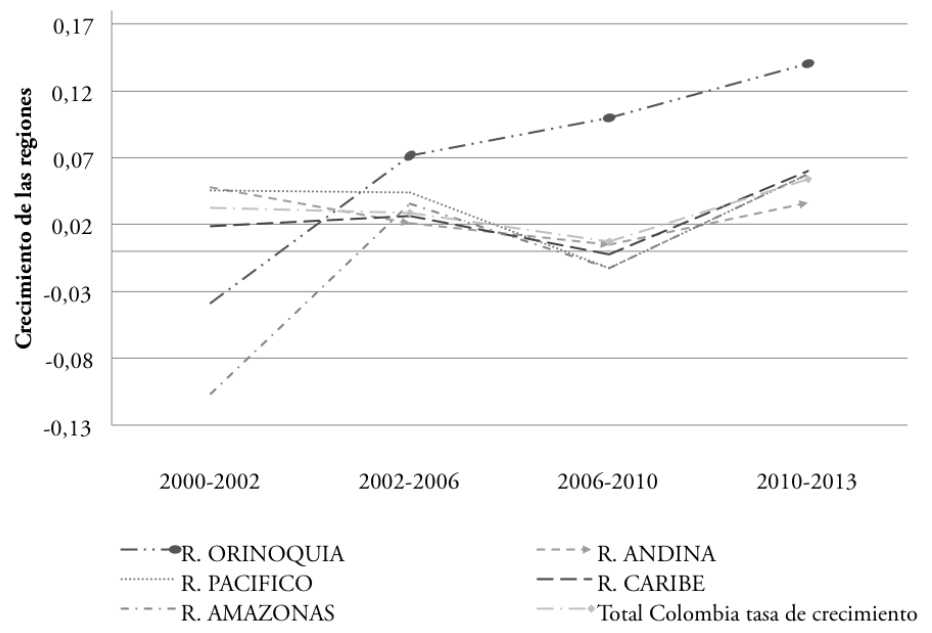

FUENTE ELABoración PRopia A PARTIR DE DATOS DEL DANE

En cuanto al sector Servicios (incluyendo transporte), el producto total aumenta sostenidamente a partir del año 2002, pero la participación por regiones permanece relativamente igual, con una pequeña caída de la región Pacífico, de 15\% a 14\%. De esta situación se puede inferir que inicialmente los servicios requeridos por el sector hidrocarburos — por ejemplo, los servicios de transporte de hidrocarburos y los servicios financieros - no provenían necesariamente de la región de la Orinoquía.

El sector Servicios presentó un crecimiento bruto de 75,8\%, pero manteniendo participaciones regionales, por lo que se deduce que, pese al boom petrolero, la Orinoquía no creció más que proporcionalmente que las otras regiones por la falta de eslabonamientos hacia adelante y hacia atrás en este sector (figura 4).

Es evidente el crecimiento constante del sector Construcción a nivel nacional, con un crecimiento real de 171,4\% (figura 5). La Orinoquía aumentó su participación en los años de estudio debido al desplazamiento de los factores de producción, probablemente impulsado por la demanda de las actividades petroleras. Aunque es tentador relacionar este aumento de participación en el sector Construcción con la enfermedad holandesa, también puede ser reflejo de decrecimiento de las posibilidades de expansión en la región Andina, al contrario de las regiones periféricas como la Amazónica, la Orinoquía y el mismo Caribe.

Parte del aumento en la construcción se generó por la migración de mano de obra, especialmente calificada, población que precisa de alojamiento. Las migraciones y contrataciones de personal ajeno a los territorios han generado conflictos entre los habitantes locales y con las empresas, ya que los pobladores se ven a sí mismos como ajenos al proceso productivo y no perciben directamente los beneficios del auge cuando no trabajan. Se pretendió solucionar reglamentariamente las protestas generadas por esta situación mediante la aplicación del Decreto 2.089 de 2014, que establece cuotas mínimas obligatorias de personal local en la exploración y producción de hidrocarburos (Colombia, Ministerio de Trabajo, 2014), sin efectos reales. 
FIGURA 4 Participación porcentual y tasas de crecimiento promedio del sector Servicios

\section{Panel a}

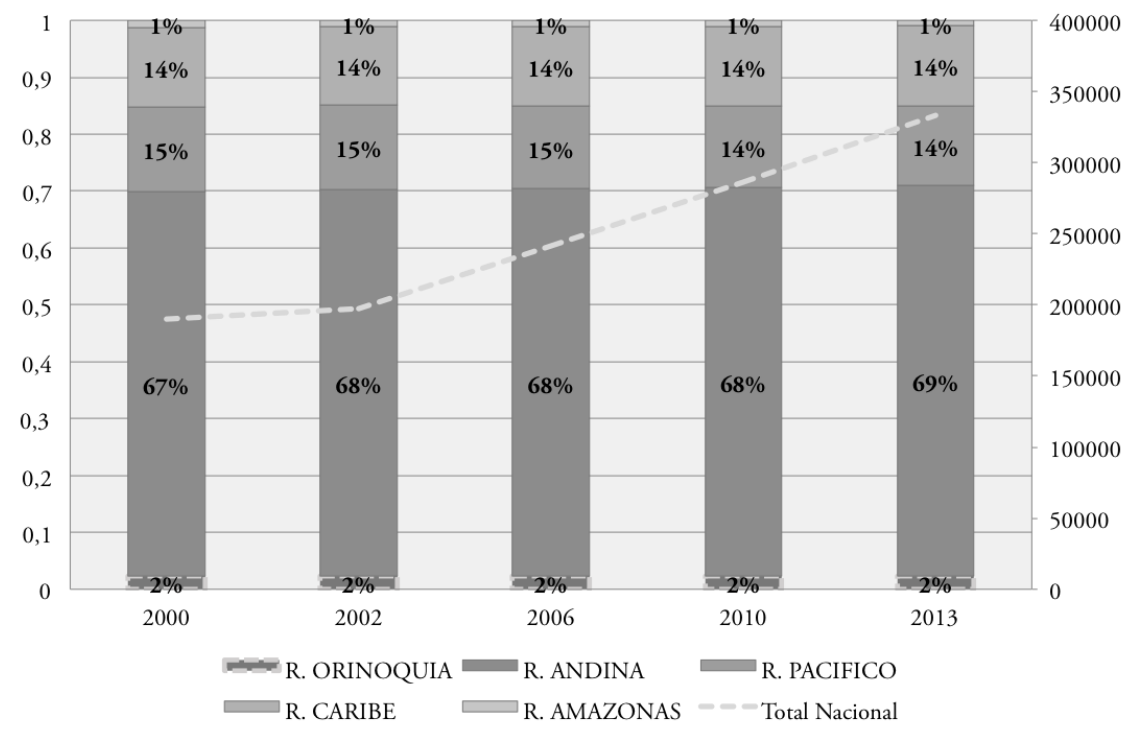

Panel b

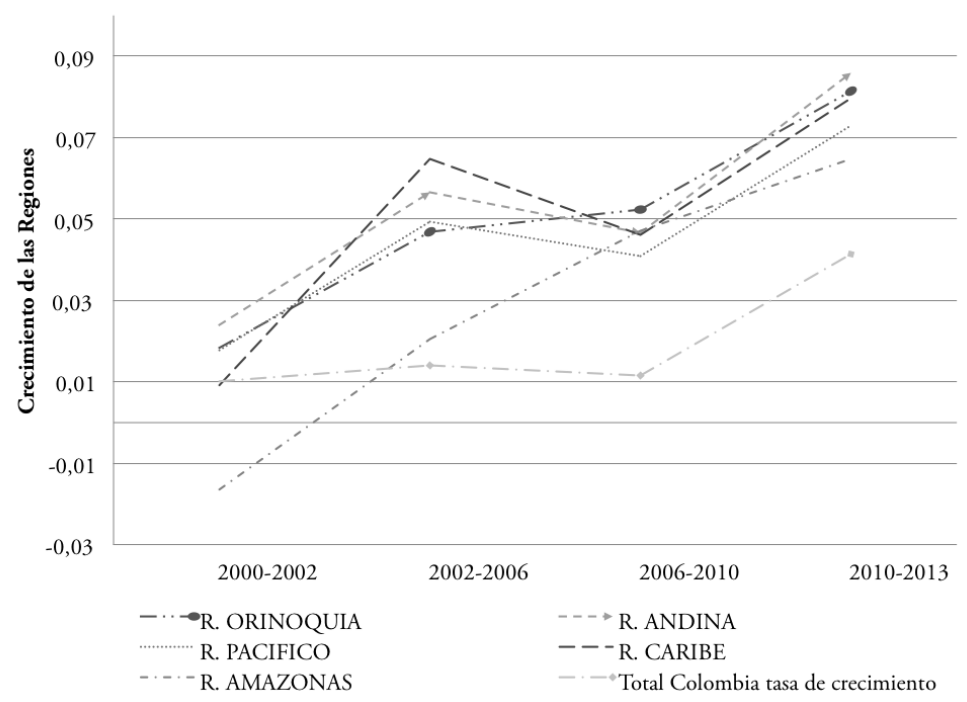

FUENTE ELABORACIÓN PROPIA A PARTIR DE DATOS DEL DANE 
FIGURA 5 | Participación porcentual y tasas de crecimiento promedio del sector Construcción

Panel a

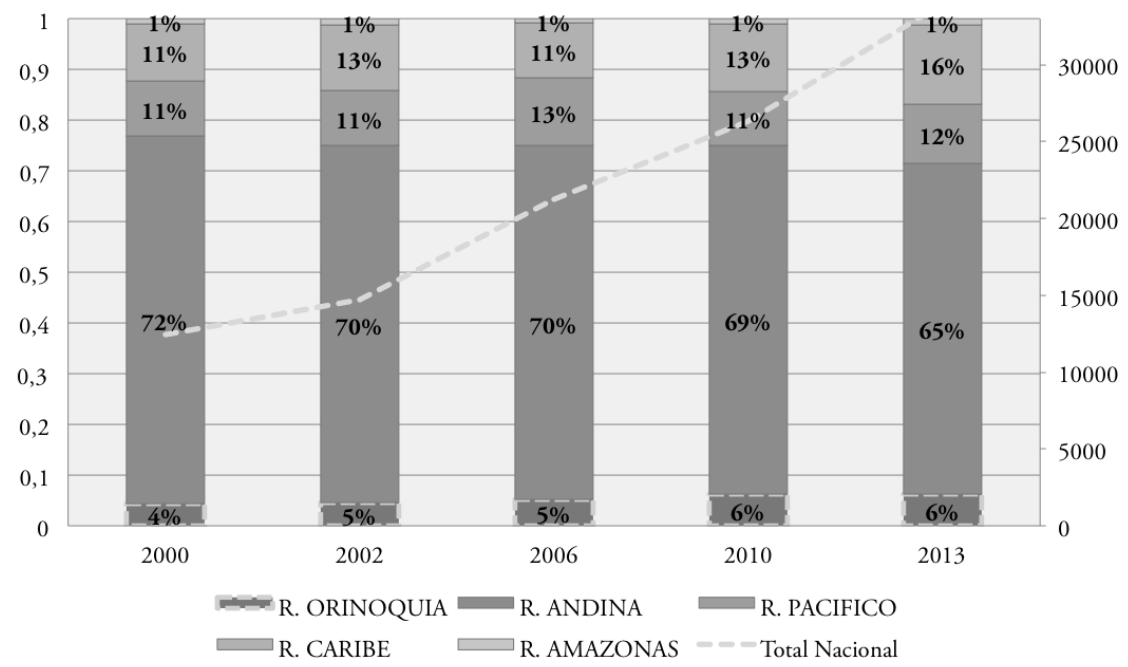

Panel b

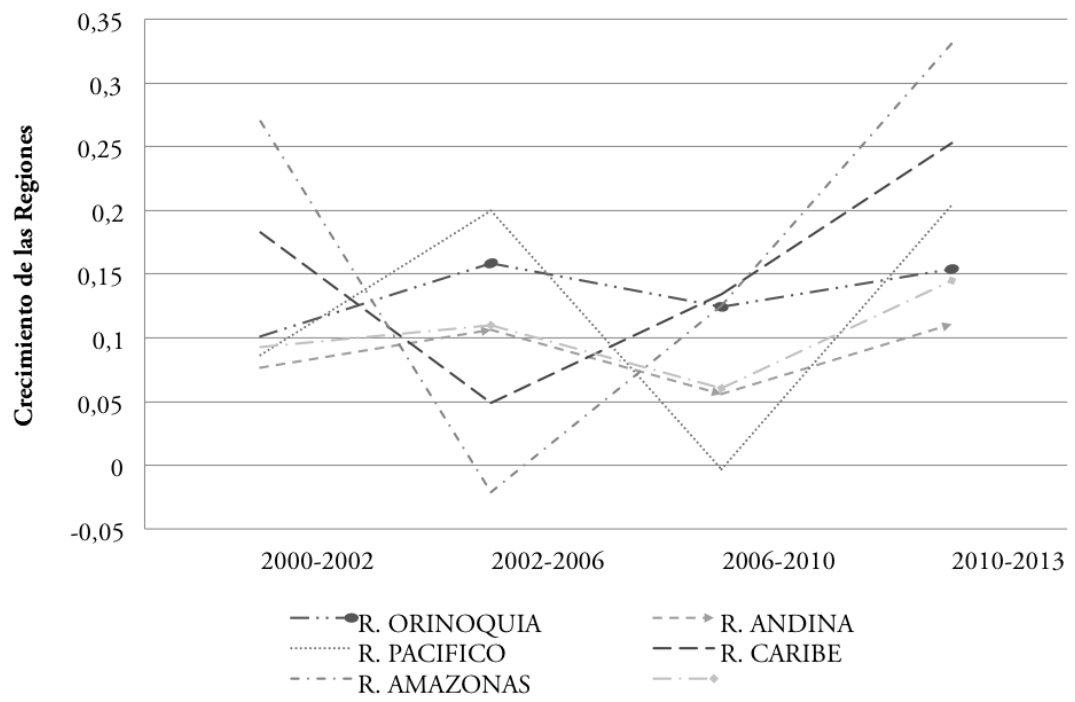

FUENTE ELABORACIÓN PROPIA A PARTIR DE DATOS DEL DANE 
En lo referente al sector de minería (figura 6), las regiones pequeñas en cuanto a participación son la Pacífico y la Amazonia, con no más de 3\% cada una. Entre tanto, la región Orinoquía muestra una participación variable de entre 42\% y 54\% en los años estudiados, principalmente basada en petróleo y gas. Por su parte, las participaciones de la región Andina pertenecen a carbón (de pequeña minería principalmente), esmeraldas y oro, entre otras. Por otro lado, la región Caribe tiene fuerte asiento en la minería de carbón a gran escala.

Es importante señalar que, para el año 2006, la producción minera comenzaba a recuperarse, luego de una pequeña caída del sector a nivel nacional en los últimos años de la administración Pastrana. La producción de petróleo entre 2004 y 2006 fue de alrededor de 530 mil barriles por día calendario. Al llegar el año 2010, la producción alcanzaba 789 mil barriles diarios calendario (Colombia, Ministerio de Minas y Energía / Agencia Nacional de Hidrocarburos [ANH], 2014). Esa recuperación del sector tiene que ver con una intensificación de la exploración y explotación, sobre todo en la Orinoquía. La tasa bruta real de crecimiento del sector minería de la serie $2000-2013$ fue de $67,2 \%$

FIGURA 6 | Participación porcentual y tasas de crecimiento promedio del sector Minería

\section{Panel a}

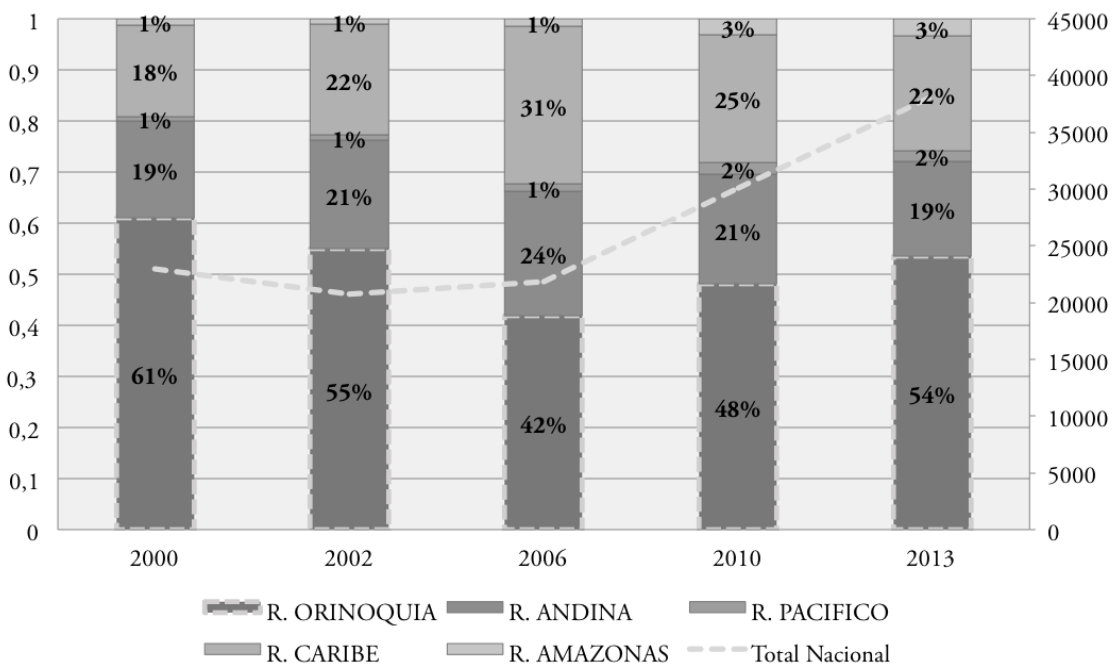




\section{Panel b}

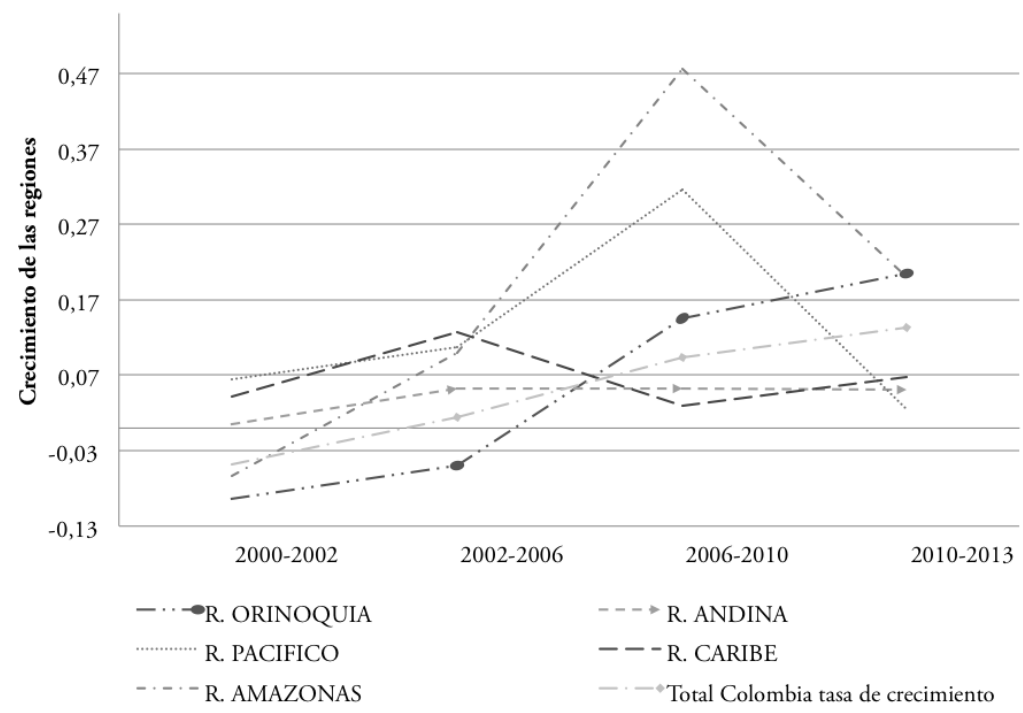

FUENTE ELABORACIÓN PROPIA A PARTIR DE DATOS DEL DANE

El sector industrial (figura 7), pese a tener un crecimiento total del $43,4 \%$ en el periodo de análisis, presentó una desaceleración del crecimiento, primero en el periodo 2000-2002 y luego en el periodo 2006-2013. En el periodo 2002-2006 el crecimiento industrial fue significativo. Vale anotar que el índice mensual de actividad manufacturera no reporta subidas o caídas de actividad mensual más allá del 10\% como máximo (Banco de la República, Índice de actividad manufacturera); además, las tasas anuales de crecimiento real del sector no superaron el 5\%.

La región Orinoquía decreció en su participación, debido probablemente a su concentración en el sector minero, tendencia relacionada con el diferencial salarial intersectorial. Por dicho diferencial salarial en la Orinoquía, la industria tendría dificultades de costos para crecer, lo mismo que la agricultura de cultivos tradicionales.

Una situación similar se dio en regiones como Caribe y Andina, las cuales presentaron decrecimientos entre los años 2002 y 2010, y luego una leve recuperación. Cabe recordar que estas regiones concentran la industria manufacturera y fueron principalmente golpeadas por la apreciación del peso colombiano (COP).

La evolución del piB presenta en general un rápido crecimiento desde el año 2002, y la composición regional de este no varió mucho debido a -como se explicó anteriormente- el buen comportamiento del sector de la construcción junto con el de la minería, que impulsaron el pIB. La tasa de crecimiento en el periodo fue de $73,1 \%$. 
FIGURA 7 Participación porcentual y tasas de crecimiento promedio del sector Manufactura

Panel a

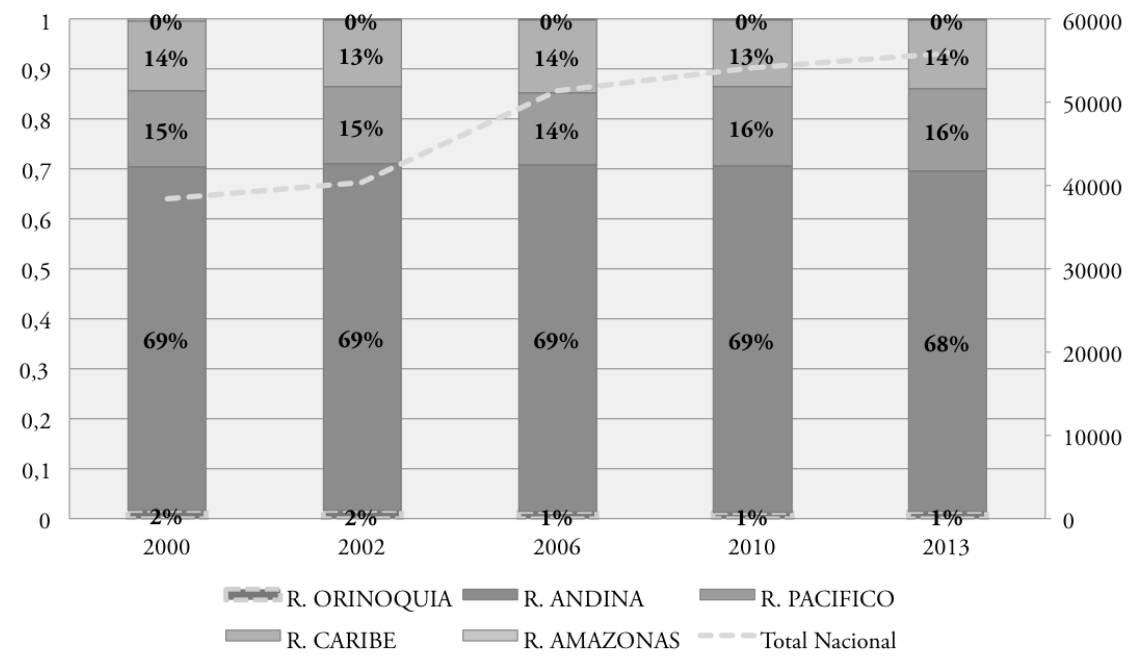

Panel b

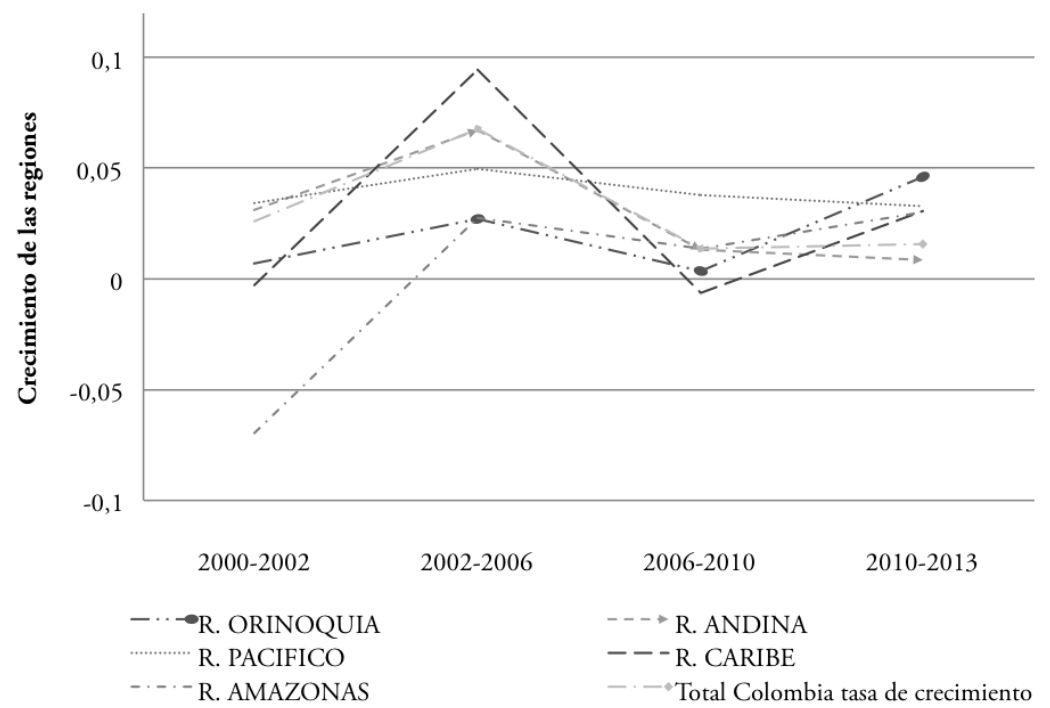

FUENTE ELABORACIÓN PROPIA A PARTIR DE DATOS DEL DANE 
FIGURA 8 | Participación porcentual y tasas de crecimiento promedio del PIB

Panel a

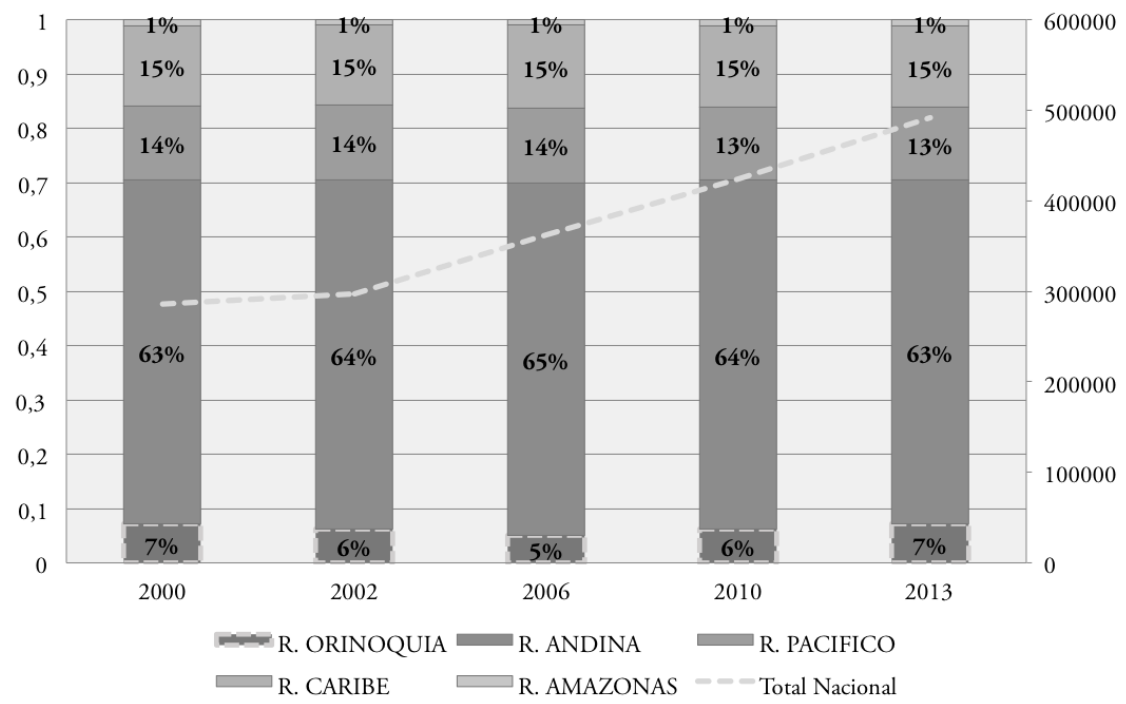

Panel b

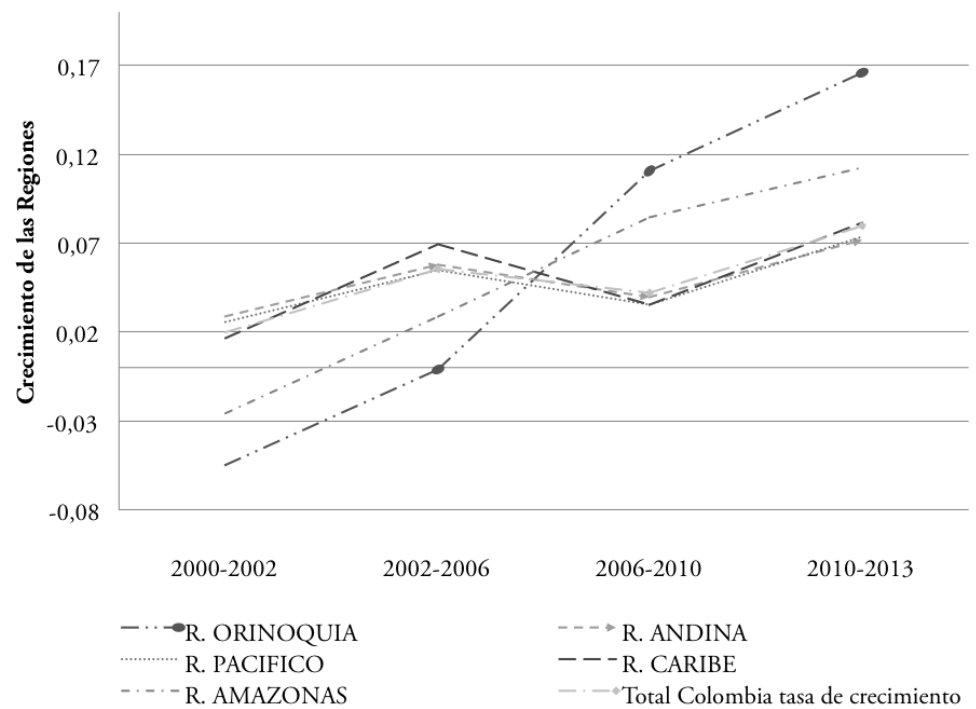

FUente Elaboración PRopia A PARTiR DE DATOS DEL DANE 
De lo anterior puede inferirse que a medida que el total de la minería presenta un crecimiento, se da una apreciación del peso colombiano respecto al dólar. Las variaciones de este sector afectan la tasa de cambio representativa del mercado (TRM) ${ }^{4}$ inversamente, como es de esperarse. Según Stijns (2003), esta situación es el primer efecto que se percibe cuando existe enfermedad holandesa.

Además de lo anterior, diferentes multinacionales están inyectando dólares por inversión extranjera directa para llevar a cabo las actividades de explotación de hidrocarburos y otras actividades a las que el gobierno ha facilitado su acceso.

\section{FIGURA 9 | Evolución de la tasa de cambio representativa del mercado (TRM), sector Minería y Petróleo}

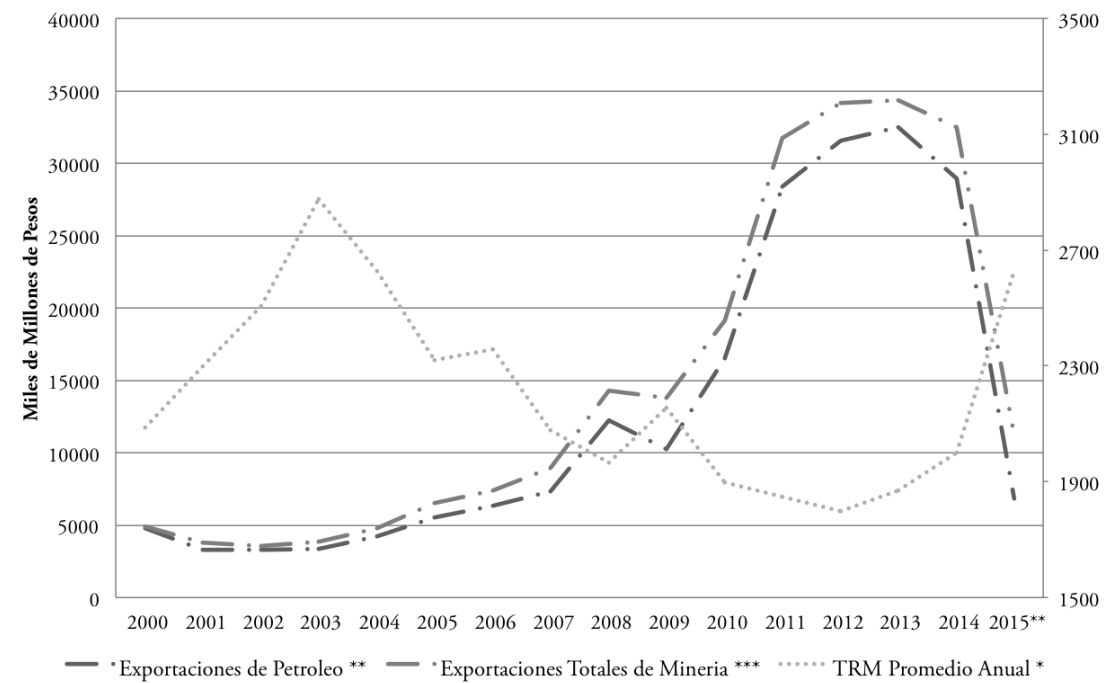

FUENTE ELABORACIÓN PROPIA EN BASE A * TRM BANCO DE LA REPÚBLICA CORTE 23 DE SEPTIEMBRE $2 O I 5$. (EJE DERECHO EXPORTACIONES TOTAL MINERÍA Y PETRÓLEO EJE IZQUIERDO PROMEDIO ANUAL TASA REPRESENTAIVA DEL MERCADO DE COLOMBIA); ** LAS EXPORTACIONES DE PETRÓlEO SON LAS REPORTADAS POR ACP HASTA ABRIL DEL 20 I 5 ; *** LAS EXPORTACIONES TOTALES DE MINERÍA SON LAS REPORTADAS POR EL DANE CORRESPONDEN HASTA EL MES DE JULIO 20 I 5

Cabe mencionar que esta apreciación de la moneda es un estímulo a las importaciones, lo que lleva a déficits en la balanza de pagos; además, desestimula las exportaciones por parte de los sectores tradicionales industriales y agrícolas del país, al disminuir su diferencial ingresos-costos en moneda local (pesos).

La tabla 1, que presenta las exportaciones tradicionales y no tradicionales, muestra que las disminuciones en exportaciones mineras tienden a ser menores que las del sector industrial. De hecho, en 2009 y 2010, mientras la minería no tradicional aumentaba, el sector industrial sufrió fuerte contracción. 
TABLA I | Exportaciones tradicionales y no tradicionales, 2000-2013

\begin{tabular}{|c|c|c|c|c|c|c|c|c|c|}
\hline \multirow{2}{*}{ AÑo } & \multicolumn{5}{|c|}{$\begin{array}{l}\text { EXPORTACIONES TRADICIONALES } \\
\text { DE COLOMBIA }\end{array}$} & \multicolumn{4}{|c|}{\begin{tabular}{|c} 
EXPORTACIONES NO TRADICIONALES \\
POR SECTOR \\
\end{tabular}} \\
\hline & TOTAL & CAFÉ & CARBÓN & PETRÓLEO & $\begin{array}{l}\text { FERRO- } \\
\text { NÍQUEL }\end{array}$ & TOTAL & AGRÍCOLA & MINEROS & $\begin{array}{l}\text { INDUS- } \\
\text { TRIALES }\end{array}$ \\
\hline 2000 & 6396,5 & 990,6 & 862,3 & 4353,1 & 190,4 & 6211,3 & 1354,8 & 133,0 & 4723,5 \\
\hline 2001 & 5481,2 & 763,8 & 1197,0 & 3285,1 & 235,2 & 6848,9 & 1368,8 & 142,4 & 5337,7 \\
\hline 2002 & 5309,5 & 772,2 & 990,5 & 3275,2 & 271,5 & 6666,0 & 1386,6 & 261,5 & 5017,9 \\
\hline 2003 & 6030,8 & 809,3 & 1422,0 & 3383,2 & 416,2 & 7097,7 & 1373,1 & 800,8 & 4923,8 \\
\hline 2004 & 7658,6 & 949,5 & 1853,7 & 4227,4 & 628,0 & 9072,4 & 1618,1 & 838,5 & 6615,8 \\
\hline 2005 & 10365,6 & 1470,7 & 2598,2 & 5559,0 & 737,8 & 10824,8 & 1969,5 & 966,4 & 7888,9 \\
\hline 2006 & 11809,5 & 1461,2 & 2913,0 & 6328,3 & 1107,1 & 12581,5 & 2156,5 & 1188,1 & 9236,8 \\
\hline 2007 & 14207,0 & 1714,3 & 3494,5 & 7317,9 & 1680,3 & 15784,3 & 2658,3 & 1171,5 & 11954,5 \\
\hline 2008 & 20002,8 & 1883,2 & 5043,3 & 12212,6 & 863,7 & 17623,1 & 3203,6 & 1540,3 & 12879,2 \\
\hline 2009 & 17952,5 & 1542,7 & 5416,4 & 10267,5 & 725,9 & 14893,8 & 2906,2 & 2011,2 & 9976,4 \\
\hline 2010 & 25367,7 & 1883,6 & 6015,2 & 16501,6 & 967,3 & 14345,6 & 2351,6 & 2438,9 & 9555,1 \\
\hline 2011 & 40252,5 & 2608,4 & 8396,9 & 28420,7 & 826,6 & 16662,4 & 2507,8 & 3230,6 & 10924,0 \\
\hline 2012 & 42155,3 & 1910,0 & 7805,2 & 31558,9 & 881,2 & 17969,9 & 2872,2 & 3810,2 & 11287,5 \\
\hline 2013 & 41735,1 & 1883,9 & 6687,9 & 32483,1 & 680,1 & 17088,6 & 3049,0 & 2647,0 & 11392,6 \\
\hline
\end{tabular}

NOTA DATOS EN MILES DE MILLONES DE DÓLARES FOB

FUENTE BANCO DE LA REPÚBLICA DE COLOMBia

En la tabla 2 se observa cómo la Orinoquía ganó participación de los sectores agropecuario y de la construcción, mientras que perdió en el sector minero y en el industrial. Al mismo tiempo, se destaca la gran importancia de la región Andina en los cinco sectores aquí analizados, con excepción de la minería.

TABLA 2 | Participación porcentual de las regiones según sector, años 2000 y 2013

\begin{tabular}{|c|c|c|c|c|c|c|c|c|c|c|c|c|}
\hline \multirow{2}{*}{ SECTOR } & \multicolumn{2}{|c|}{ ORINOQUÍA\% } & \multicolumn{2}{|c|}{ ANDINA \% } & \multicolumn{2}{|c|}{ PACÍFICO \% } & \multicolumn{2}{|c|}{ CARIBE \% } & \multicolumn{2}{|c|}{ AMAZONIA\% } & \multicolumn{2}{|c|}{ COLOMBIA N } \\
\hline & 2000 & 2013 & 2000 & 2013 & 2000 & 2013 & 2000 & 2013 & 2000 & 2013 & 2000 & 2013 \\
\hline Agropecuario & 7 & 11 & 57 & 55 & 15 & 15 & 19 & 18 & 2 & 2 & 22.661 & 30.639 \\
\hline Minero & 61 & 54 & 19 & 19 & 1 & 2 & 18 & 22 & 1 & 3 & 22.993 & 38.144 \\
\hline Industria & 2 & 1 & 69 & 68 & 15 & 16 & 14 & 14 & 0,30 & 0,20 & 38.409 & 55.875 \\
\hline Servicios & 2 & 2 & 67 & 69 & 15 & 14 & 14 & 14 & 1 & 1 & 189.642 & 333.345 \\
\hline Construcción & 4 & 6 & 72 & 65 & 11 & 12 & 11 & 16 & 1 & 1 & 12.435 & 33.943 \\
\hline
\end{tabular}

FUENTE ELABORACIÓN PROPIA CON BASE EN DATOS DANE 


\section{Marco institucional: \\ modernizaciones institucionales óptimas pero desafortunadas}

En este apartado se describe la situación de Colombia en relación con las condiciones institucionales que inciden en la posibilidad de evitar la maldición de los recursos naturales, sintetizada en la figura 1: apertura del mercado, reformas políticas y distribución igualitaria, y gasto eficiente en transferencia directa.

En ese orden de ideas, con respecto a la condición 1 (apertura del mercado), el país, desde inicios de los noventa, comenzó una carrera aperturista que en la última década se ha materializado en innumerables acuerdos de libre comercio, por lo que no se le podría caracterizar como una economía cerrada proteccionista para el periodo de análisis.

En relación con la condición 2, es necesario considerar la existencia de facciones políticas en disputa por las rentas generadas por los RN, respecto de lo cual Restrepo (2011) destaca la participación de empresas mineras y petroleras, entre otras, en la financiación de las campańas políticas. Teniendo en cuenta el pasado colonial espańol, ello llevaría a pensar en una persistencia institucional a través de elites que resguardan una estructura social que las favorece. Otra alusión a esto se encuentra tangencialmente en el estudio de Perry y Olivera (2009), donde se usan variables institucionales, como la presencia de grupos guerrilleros y paramilitares en municipios, encontrándose incidencias importantes en la distribución de las rentas generadas por los RN, como resultado de las extorsiones y hasta las capturas institucionales de los entes territoriales.

En relación con la condición 3, gasto eficiente de los recursos en contraposición a la generación de empleo burocrático y aumento del gasto público en los últimos ańos, se encontró que en los últimos años ha habido un redireccionamiento positivo de las políticas hacia la eficiencia en el gasto. ${ }^{5}$ En ese proceso, se pasó de un esquema según el cual las entidades locales tenían una importante participación en el gasto de los recursos - con sujeción a ciertos parámetros para el porcentaje gastado en Necesidades Básicas Insatisfechas (NBI), salud y educación-, a un esquema de distribución en que la mayoría de las regalías es administrada por el Gobierno Central.

Según María Gutiérrez (2014), el cambio en el Sistema General de Regalías (sGR) durante el año 2012 y 2013 ha terminado priorizando el uso de los recursos fiscales disponibles para la inversión en el sector de las infraestructuras de transporte. ${ }^{6}$ Es probable que esto mude la pereza fiscal y la voracidad que Perry y Olivera (2009) identificaron, y que podría ser síntoma de que en presencia de un auge en RN y alta percepción de regalías por parte de las entidades estatales, la disposición a pagar por los servicios estatales (disposición a pagar impuestos, o "Q" de Tobin) por parte de la sociedad disminuya.

5 Este movimiento, que produjo un cambio en el sistema general de regalías (sGR), se presentó solo después del periodo de análisis cubierto por este estudio.

6 Mediante el Sistema General de Regalías (SGR) se determina la distribución, objetivos, fines, administración, ejecución, control, el uso eficiente y la destinación de los ingresos provenientes de la explotación de los recursos naturales no renovables, precisando las condiciones de participación de sus beneficiarios. En https://www.sgr.gov.co/Qui\%C3\%A9nesSomos/SobreelSGR.aspx [N. de E.]. 
Si esto último es cierto, a los gobernantes les resultaría política y fiscalmente más beneficioso relajar la protección ambiental, para obtener más recursos. Sin embargo, recientemente, un fallo de la corte constitucional colombiana detuvo la continuación de la exploración indiscriminada con afectaciones a indígenas, campesinos y al medioambiente (Centro de Estudios para la Justicia Social - Tierra Digna, 2015).

En cuanto a las políticas de desarrollo local y regional, y aquellas para el desarrollo regional, 7 ellas han disminuido en importancia, toda vez que los Consejos Regionales de Planificación (CORpes), con la entrada del nuevo milenio, parecen haber perdido influencia en la coordinación de políticas de desarrollo. Los CORPES, nacidos en 1975 como agrupaciones de departamentos, tienen entre sus funciones la búsqueda de un desarrollo interregional equilibrado, el fortalecimiento de las entidades territoriales regionales y preparar planes de desarrollo regional (Massiris, 2010). No obstante tal definición, tras su pérdida de peso institucional, lo que ha ganado importancia son las políticas sectoriales, que a veces coinciden con alguna región específica. Ejemplo de ello es la situación de los sectores del café, caña y leche, este último con un documento del Consejo Nacional de Política Económica y Social (conpes) ${ }^{8}$ (véase Szegedy-Maszák, 2014, pp. 372-373), direccionado principalmente al desarrollo de la Mojana y la Altillanura.

La región Orinoquía, en sus unidades territoriales favorecidas con las regalías bajo el anterior Sistema General de Regalías (SGR), tuvo la oportunidad de gerenciar su desarrollo, aunque con ciertas restricciones impuestas por la Ley 141 de $1994,{ }^{9}$ sobre la destinación porcentual de las regalías, que obligó a destinarlas de la siguiente forma: (i) 60\% para la atención y mejoramiento de indicadores de salud, educación, mortalidad infantil, agua potable y alcantarillado; (ii) 30\% libre destinación (inversión); (iii) 5\% gastos de funcionamiento u operación; y (iv) 5\% interventorías técnicas (Ley 756 de 2002, art. 13).

Dada la normativa actual, si antes los entes solo tenían un 30\% de las regalías para intentar incidir mediante inversión en el crecimiento económico, ahora, con el nuevo Sistema General de Regalías, crearon tres fondos de carácter regional: el Fondo de Compensación Regional (FCR), el Fondo de Desarrollo Regional (FDR) y el Fondo de Ciencia, Tecnología e Innovación (FCTI). Estos Fondos, según un principio de distribución uniforme de regalías, deben aprobar proyectos con múltiple impacto en varios departamentos.

Las dos primeras son de origen en las propias entidades regionales y locales, mientras que la segunda es la actuación del Estado nacional para desarrollar una región concreta.

8 Sobre el Consejo Nacional de Política Económica y Social, véase nota del Departamento Nacional de Planeación, Colombia, donde se señala: "El Consejo Nacional de Política Económica y Social -CONPES- fue creado por la Ley 19 de 1958. Esta es la máxima autoridad nacional de planeación y se desempeńa como organismo asesor del Gobierno en todos los aspectos relacionados con el desarrollo económico y social del país. Para lograrlo, coordina y orienta a los organismos encargados de la dirección económica y social en el Gobierno, a través del estudio y aprobación de documentos sobre el desarrollo de políticas generales que son presentados en sesión" (en https:// www.dnp.gov.co/CONPES/Paginas/conpes.aspx). [N. de E.]

9 La Ley 141 destinaba a las entidades productoras un 80\%, y al Fondo Nacional de Regalías (FNR) se le debía asignar un $20 \%$. 
En el nuevo SGR se contempla también contribuir a disminuir la volatilidad cambiaria a través de la creación del Fondo de Ahorro y Estabilización (FAE), para hacer concordante la política fiscal con el gasto de las regalías, procurando así la estabilidad macroeconómica.

Pese a estas modificaciones del marco fiscal y a la audacia de los gobiernos locales donde se presentó el boom, para, de un lado, aprovechar las rentas de forma fiscalmente inteligente $y$, de otro, atenuar los impactos regionales de la mudanza en el Sistema de Regalías, la región de Orinoquía pasará por una desaceleración de la cual solo podrá sacarla otro auge, el de los recursos naturales difusos. En los municipios de la Altillanura, entre 2000 y 2011, el área agrícola creció de 2.929.518 hectáreas a 3.848.724 hectáreas (Instituto Geográfico Agustín Codazzi [IGAC], Universidad de Los Andes [Uniandes] \& Universidad de Antioquia, 2012).

Es de aclarar que el boom petrolero sigue presentándose en la región productora, en el sentido de que no se ha llegado al agotamiento del recurso natural; más bien, disminuyeron los beneficios económicos y la rentabilidad de su extracción. Precisamente la renta petrolera que esperaba recibir el gobierno nacional para fines de 2015 disminuía su importancia con respecto al total de sus ingresos. En 2013, la renta petrolera fue el 19,7\%; en 2014 fue el 15,6\%; para 2015, se esperaba que fuera apenas 7,3\%; y en los siguientes ańos se esperaría apenas un 2,5\% (Colombia, Ministerio de Hacienda, 2015), lo que significa una caída de renta petrolera del orden de 2 billones en 2015 y de 11 billones para 2016 (Inteligencia Petrolera, 2015).

Lo anterior hace pensar que, en realidad, las reformas fueron infortunadas y llegaron tarde en el periodo de auge petrolero (ańos noventa hasta 2014 y parte de 2015), opuesto a lo que plantearon Reina, Alejo y Devia (2015). Por tanto, es previsible que las desaceleraciones y decrecimientos, que otros sectores de la economía sufrieron durante el periodo de auge, se reviertan en términos relativos. Sin embargo, de entrada se puede prever una apreciable perdida de know-how en las industrias, así como una permanencia de la condición periférica de la Orinoquía, en el sentido económico, con desequilibrios en la estructura productiva más marcados.

\section{Conclusiones}

La evolución de la tasa de cambio representativa del mercado (TRM) con respecto a la minería, y especialmente a las exportaciones de petróleo, confirma uno de los puntos de partida de este estudio: el boom de los recursos naturales como condición necesaria para la existencia de enfermedad holandesa en Colombia.

La otra condición vital para el diagnóstico de enfermedad holandesa, la caída de exportaciones industriales, no se cumple estrictamente para Colombia. No obstante, su participación disminuyó, ya que el total exportado aumentó 652,5\% en el periodo, mientras que la industria apenas dobló sus exportaciones. En un análisis regional, producto de la enfermedad holandesa el crecimiento industrial perdió fuerza en la Orinoquía, mientras que en el Pacífico subió.

La apreciación del peso colombiano ha hecho que las tasas de crecimiento de la industria manufacturera sean menores en comparación con los otros sectores no transables, como construcción y servicios (Orinoquía), por la concentración de 
la economía en el sector petrolero. Al mismo tiempo, en el periodo en estudio se observa que la industria manufacturera disminuyó sus tasas de crecimiento en todas las regiones hasta el año 2010; tal es el caso de la Andina, que tuvo tasas de crecimiento de 7\% en el periodo 2002-2006, mientras en el lapso 2006-2010 su tasa de crecimiento disminuyó al 1\%. Esta situación se repite en todas las regiones de Colombia, evidenciando otro de los efectos visibles de la enfermedad holandesa, ya que si bien el sector transable no presentó tasas de decrecimiento, sí se vio afectado su ritmo de crecimiento.

Sí hay enfermedad holandesa, aunque moderada, según las señaladas condiciones 1 y 4 (apreciación del tipo de cambio y disminución de las exportaciones manufactureras). Aunque se desconocen los datos sectoriales regionales de los años 2013 y 2014, Colombia estaría cayendo virtualmente en la maldición de los recursos naturales entre 2015 y 2016, viendo fuertemente frenado su crecimiento. Esto pese a medidas de modernización institucional óptimas, como direccionar las instituciones a la inversión en infraestructura y la implementación de la regla fiscal, las cuales no fueron del todo las mejores, ya que no encauzaban las regalías hacia transferencias directas para los ciudadanos. De otro lado, los niveles de apropiabilidad estarían en entredicho, dado el ambiente de corrupción campante en el país, por lo que futuros estudios deberían detallar cualitativa y cuantitativamente la apropiabilidad de los recursos naturales en Colombia.

Algunos autores indican que, por efectos de enfermedad holandesa, se puede ubicar una economía en la situación de maldición de los recursos naturales. Al respecto, creemos que las alteraciones en el corto plazo por un auge son inevitables, pero que, sin embargo, pueden ser moderadas con el adecuado marco institucional.

En la mayoría de casos, los sectores en auge se han conformado como enclaves, generando problemas en la participación directa de la población en ellos, lo que a su vez ocasiona protestas de habitantes locales con pretensión de trabajar en las empresas que están desarrollando la actividad de extracción de recursos naturales. Estos efectos son consistentes con la literatura.

A diferencia del estudio de maldición de recursos naturales de Perry y Olivera (2009), aquí se ha optado por un análisis regional en que se agrupa departamentos, en vez de tomarlos como unidades de análisis. Tal decisión permite mejorar el análisis conjunto de la Orinoquía, con tres departamentos productores de petróleo, aunque se pierde capacidad analítica para la región Caribe, donde la producción minera se concentra en el carbón de la Guajira.

La atipicidad del caso colombiano radica en que normalmente el sector agropecuario se tipifica como un sector transable. De acuerdo con la literatura sobre enfermedad holandesa, el sector agropecuario se asemeja al sector manufacturero. Entonces este sector debió contraerse, o al menos disminuir su ritmo de crecimiento. Pero gracias a la reciente expansión agrícola en la región de la Orinoquia, su sector agropecuario creció. En última instancia, para el caso colombiano de enfermedad holandesa se presentaron dos auges en recursos naturales: el minero, basado en petróleo; y el agropecuario, basado en la ampliación de su frontera agrícola.

En definitiva, se ha demostrado que la enfermedad holandesa afectó en buena medida a los sectores de productos transables no mineros, disminuyendo sus tasas 
de crecimiento sectorial, al mismo tiempo que los sectores no transables aumentaron su participación en la dinámica nacional. Con lo anterior, es previsible que en el futuro se evidencie que Colombia sufre de la maldición de RN a causa de la desaceleración económica, que implica la caída en el valor de exportaciones mineras, especialmente petroleras.

\section{Agradecimientos}

Los autores agradecen por las revisiones y sugerencia a borradores de este articulo a Milton Robles, Oscar Hernández, Wilson Ramírez y los pares evaluadores. Sus sugerencias mejoraron sustancialmente este trabajo. Además, Luis Reina-Bermúdez (orcid.org/0000-0003-0674-7159) agradece al Programa de Alianzas para la Educación y la Capacitación (PAEC) entre la Organización de los Estados Americanos (OEA) y el Grupo Coimbra de Universidades Brasileñas (GCUB) que posibilitó sus estudios de Maestría en Desarrollo Regional de la Amazonia en la UFRR entre 2014 y 2016.

Didier Alejo-Barrera agradece al Fondo de Educación Superior de la Gobernación del Meta (FES) que permite adelantar sus estudios de maestría en Gobierno y Políticas Públicas en la Universidad Externado de Colombia.

Neider Devia-Merchan agradece a la Universidad del Tolima y al Acuerdo Específico de Cooperación para el Intercambio de Estudiantes Brasil-Colombia RACOL- Firmado entre el Grupo Coímbra de Universidades Brasileiras (GCUB) y la Asociación Colombiana de Universidades (ASCUN) del año 2015, que apoyaron el intercambio académico de un semestre en la Universidades Federal de Roraima, Brasil.

\section{Referencias bibliográficas}

Acemoglu, D. \& Robinson, J. A. (2012). Por qué fracasan los paises. Los origenes del poder, la prosperidad y la pobreza. Barcelona: Deusto.

Arezki, R. \& Van der Ploeg, R. (2007). Can the natural resource curse be turned into a blessing? The role of trade policies and institutions. IMF [International Monetary Fund] Working Papers, 1-34. En https://www.imf.org/external/pubs/ft/wp/2007/wp0755.pdf

Auty, R. (1997). Natural resources endowment, the State and development strategy. Journal of International Development, 9(4), 651-663. https://dx.doi.10.1002/(SICI)10991328(199706)9:4<651::AID-JID474>3.0.CO;2-4

Auty, R. (2001). The political economy of resource-driven growth. European Economic Review, 45(4-6), 839-846. https://dx.doi.org/10.1016/S0014-2921(01)00126-X 
Auty, R. \& Gelb, A. H. (2000). Political economy of resource abundant states. Annual Bank Conference on Development Economics in Paris. June of 2000. En http://www-wds. worldbank.org/servlet/WDSContentServer/IW3P/IB/2004/04/29/000265513_2004 0429114636/Rendered/PDF/28750.pdf

Banco de la República de Colombia, n.f. (2013). Índice de producción real de la industria manufacturera colombiana. En http://www.banrep.gov.co/es/contenidos/page/total-yprincipales-sectores

Birdsall, N., Pinckney, T. C. \& Sabot, R. H. (1999). Equity, Savings, and Growth. Center on Social and Economic Dynamics.

Boschini, A., Pettersson, J. \& Roine, J. (2007). Resource curse or not: A question of appropriability. Scandinavian Journal of Economics, 109(3), 593-617. https:// dx.doi.10.1111/j.1467-9442.2007.00509.x

Bruno, M. \& Sach, J. (1982). Energy and resource allocation: A dynamic model of the Dutch disease. Review of Economic Studies, 49(5), 845-859. https://dx.doi.10.2307/2297191

Bulmer-Thomas, V. (1994). The economic history of Latin America since independence. Cambridge Latin American Studies. Camabridge, uK / New York: Cambridge University Press.

Centro de Estudios para la Justicia Social - Tierra Digna (2015, 15 de mayo). Suspendidas 516 áreas estratégicas mineras que ocupan el 20.3\% del país. En Agencia Prensa Rural, http://prensarural.org/spip/spip.php?article16853

Collier, P. (2006). African growth: Why a 'big push'? Journal of African Economies, 15(suppl 2), 188-211. https://dx.doi.org/10.1093/jae/ej1031

Colombia. Ministerio de Hacienda y Crédito Público (2015, 10 de septiembre). Boletín 127: El país ha logrado acomodarse a la menor renta petrolera. En http://bit.ly/2qBGqwW

Colombia. Ministerio de Minas y Energía \& Agencia Nacional de Hidrocarburos (ANH). (2015). Informe estadistico petrolero. En https://www.acp.com.co/index.php/es/ informe-estadistico-petrolero-iep

Engerman, S. \& Sokoloff, K. (1994). Factor endowments, institutions, and differential paths of growth among new world economies: A view from economic historians of the United States. NBER (National Bureau of Economic Research) Working paper No. 66. En http:// www.nber.org/papers/h0066

Engerman, S. \& Sokoloff, K. (2002). Factor endowments, inequality, and paths of development among new world economics. NBER (National Bureau of Economic Research) Working paper No. 9259. En http://www.nber.org/papers/w9259

Escobar, A. 2005. El "postdesarrollo" como concepto y práctica social. Políticas de economía, ambiente y sociedad en tiempos de globalización. (pp. 17-31). En D. Mato (Coord.), Politicas de economía, ambiente y sociedad en tiempos de globalización (pp. 17-31). Caracas: Facultad de Ciencias Económicas y Sociales, Universidad Central de Venezuela. En http://cedum.umanizales.edu.co/mds/ch4/dsh/unidad1/pdf/El postdesarrollo como concepto.pdf

Frankel, J. A. (2012). The natural resource curse: A survey of diagnoses and some prescriptions. hks Faculty Research Working Paper Series RWP12-014. John F. Kennedy School of Government, Harvard University. En https://dash.harvard.edu/handle/1/8694932

Gelb, A. (1988). Oil windfalls: Blessing or curse? New York: Oxford University Press for the World Bank. 
Gylfason, T. (2000). Resources, agriculture, and economic growth in economies in transition. Kyklos, 53(4), 337-361. En http://onlinelibrary.wiley.com/doi/10.1111/14676435.00133/full

Gylfason, T., Herbertsson, T. T. \& Zoega, G. (1999). A mixed blessing. Macroeconomic dynamics, 3(02), 204-225. En https://notendur.hi.is/gylfason/_borders/pdf/mixedblessing.pdf

Gutiérrez, M. A. 2014. Incidencia del nuevo sistema general de regalías en el proceso de planificación del departamento del Meta en el 2012. Trabajo de Grado para optar al título de Politóloga, Facultad de Ciencia Política y Gobierno, Universidad Colegio Mayor Nuestra Señora del Rosario, Bogotá. En http://bit.ly/2rjFT5C

Instituto Geográfico Agustín Codazzi (IGAC). (2012). Atlas de la distribución de la propiedad rural en Colombia. Bogotá: Imprenta Nacional de Colombia. En http://bit.ly/1Fz9ry4

Isham, J., Woolcock, M., Pritchett, L. \& Busby, G. (2005). The varieties of resource experience: Natural resource export structures and the political economy of economic growth. The World Bank Economic Review, 19(2), 141-174. https://dx.doi.org/10.1093/wber/ lhi010

Kosacoff, B. \& Campanario, S. (2007). La revalorización de las materias primas y sus efectos en América Latina. Documentos de proyectos [Lc/Bue/w.I7]. Santiago de Chile: Comisión Económica para América Latina y el Caribe (CEPAL). En http://repositorio. cepal.org/bitstream/handle/11362/3561/1/S2007306.pdf

Massiris, C. Á. (2000). Ordenamiento territorial y procesos de construcción regional. Santafé de Bogotá. (s/d).

Inteligencia Petrolera (2015). Colombia y el impacto del petróleo. Presupuesto 2016 o la vuelta a la austeridad. Inteligencia Petrolera [Revista digital]. En http://inteligenciapetrolera. com.co/inicio/colombia-y-el-impacto-del-petroleo-presupuesto-2016-o-a-la-vuelta-ala-austeridad-por-redaccion-ip/

Mehlum, H., Moene, K. \& Torvik, R. (2006). Institutions and the resource curse. The Economic Journal, 116(508), 1-20. http://dx.doi.10.1111/j.1468-0297.2006.01045.x

Ministerio del trabajo, (2014). Decreto 2089 de 2014. Por el cual se adoptan medidas especiales para garantizar la vinculación de mano de obra local a proyectos de exploración y producción de hidrocarburos. En http://www.mintrabajo.gov.co/component/docman/ doc_download/2364-decreto2089de2014.html

Murphy, K. M., Shleifer, A. \& Vishny, R. W. (1988). Industrialization and the big push. NBER (National Bureau of Economic Research) Working Paper No. 2708. http:// dx.doi.10.3386/w2708

Piraján Díaz, J., Urrea, I. L. \& Gutiérrez, D. (2012). Enfermedad Holandesa. El auge del sector minero energético colombiano 2000-2010. Ensayo. Bogotá: Universidad Nacional de Colombia.

Perry, G. \& Olivera, M. (2009). El impacto del petróleo y la minería en el desarrollo regional y local en Colombia. CAF Documento de trabajo No 2009/06. En http://bit.ly/2rjCrI4

Reina Bermudez, L. E., Alejo Barrera, D. A. \& Devia Merchan, N. (2015). Efectos regionales de la enfermedad holandesa. Caso de estudio: Colombia entre 2000-2013. VII Seminario Internacional sobre desenvolvimento regional. Santa Cruz do Sul, Universidade de Santa Cruz do Sul (UnIsc), 16 de octubre de 2015. En https://works.bepress.com/ luis_reinabermudez/1/ 
Restrepo, N. (2011). Financiamiento de los partidos, movimientos políticos y campañas electorales en Colombia. En P. Gutiérrez \& D. Zovatto (Coords.), Financiamiento de los partidos políticos en América Latina (pp. 185-224). Washington, D.c.: Organización de los Estados Americanos / Universidad Nacional Autónoma de México. En http:// bit.ly/2rwixaj

Rosenstein-Rodan, P. N. (1943). Problems of industrialisation of Eastern and South-Eastern Europe. The Economic Journal, 53(21o-211), 202-211. http://dx.doi.10.2307/2226317

Rosenstein-Rodan, P. N. (1961). Notes on the theory of the 'big push'. In Economic Development for Latin America (pp. 57-81). Palgrave Macmillan uk. En https://link. springer.com/chapter/10.1007/978-1-349-08449-4_3

Sachs, J. \& Warner, A. M. (1995). Natural resource. Abundance and economic growth. NBER (National Bureau of Economic Research) Working Paper, No. 5398. En http://www.nber. org/papers/w5398

Sachs, J. \& Warner, A. M. (1999). The big push, natural resource booms and growth. Journal of Development Economics, 59(1), 43-76. En http://earth.columbia.edu/sitefiles/file/ about/director/pubs/JnlofDevtEcon1999.pdf

Sachs, J. \& Warner, A. M. (2001). The curse of natural resources. European Economic Review, 45(4), 827-838. http://dx.doi.0014-2921.

Stijns, J. P. (2003). An empirical test of the Dutch disease hypothesis using a gravity model of trade. EconWPA, International Trade No. 0305001. http://dx.doi.org/10.2139/ ssrn. 403041

Szegedy-Maszák, I. (2014). Free trade and agricultural public policies for producers of milk in Colombia. Vniversitas, (128), 357-381. http://dx.doi.10.11144/Javeriana.VJ128.ftap

Van der Ploeg, F. (2006). Challenges and opportunities for resource rich economies. Discussion Paper No. 5688. En https://www.cesifo-group.de/link/pse06_vanderploeg3.pdf

Willebald, H. (2011). Natural resources, settler economies and economic development during the first globalization: Land frontier expansion and institutional arrangements. Tesis doctoral, Universidad Carlos in de Madrid, Departamento de Historia Económica e Instituciones, Madrid.

Woolcock, M., Pritchett, L. \& Isham, J. (2001). The social foundations of poor economic growth in resource-rich countries. En R. M.Auty (Ed.), Resource abundance and economic development (pp. 76-92). Oxford: Oxford University Press. http://dx.d oi.10.1093/0199275785.003.0005

Wunder, S. (1992). La enfermedad holandesa y el caso colombiano. Coyuntura Económica, 22(1), 167-190. En http://www.repository.fedesarrollo.org.co/handle/11445/2299 
